\author{
Jurnal E-KOMTEK (Elektro-Komputer-Teknik) \\ Vol. 4, No. 2 (2020) pp. 228-238 \\ https://jurnal.politeknik-kebumen.ac.id/index.php/E-KOMTEK \\ p-ISSN : 2580-3719 e-ISSN : 2622-3066
}

\title{
Pengembangan Sistem Informasi Akademik Berbasis Website di Politeknik Dharma Patria
}

\section{Sri Rahandika Heri}

Manajemen Informatika, Politeknik Piksi Ganesha, Bandung, Indonesia, 40274

E-mail : dikasri201@gmail.com

Doi : https://doi.org/10.37339/e-komtek.v4i2.405

\begin{tabular}{ll}
\hline & Diterbitkan oleh Politeknik Dharma Patria Kebumen \\
\hline Info Artikel & ABSTRAK \\
Diterima : & Penelitian ini merupakan pengembangan sistem informasi nilai untuk \\
03-12-2020 & dikembangkan menjadi sistem informasi akademik di Politeknik Dharma Patria. \\
Diperbaiki : & Penelitian ini menemukan permasalahan yaitu penginputan nilai dilakukan \\
16-12-2020 & dengan mengimport data ke database di phpmyadmin cpanel untukituakademik \\
Disetujui : & harus merubah terlebih dahulu file exel menjadi file .sql atau dikenal dengan \\
16-12-2020 & convert file, sehingga memperlambat kinerja akademik dalam mengupdate serta \\
& menambah data baru dan memiliki resiko tidak sempurnanya data yang di \\
& convert dari exel ke .sql dan sistem yang digunakan bersifat offline sehingga \\
& mahasiswa hanya bisa menggunakan sistem jika berada di kampus dengan \\
& menggunakan satu komputer akademik yang terhubung dengan database \\
& akademik. Berdasarkan permasalahan tersebut, maka dibutuhkan sistem \\
& informasi yang memudahkan kinerja akademik berbasis website sehingga bisa \\
diakses secara online, sehingga mahasiswa dapat melihat informasi akademik & tanpa harus datang ke kampus. Hasil dari penelitian berupa aplikasi website \\
& sistem akadmik dengan menggunakan framework codeigniter 3.1.11 sebagai \\
& dasar sistemnya memiliki ukuran size yang relative kecil maka lebih cepat diakses \\
& sehingga mahasiswa dapat mengakses informasi dengan mudah. \\
& Kata Kunci: Akademik, Sistem Informasi, Website
\end{tabular}

\begin{abstract}
Currently, several methods that researchers use to facilitate image processing are This research is the development of a value information system to be developed into an academic information system at the Dharma Patria Polytechnic. This study found a problem, namely that inputting values was carried out by importing data to a database in php my admin panel, so academics must first convert the exel file into a sql file or known as the convert file, so that it slows down academic performance in updating and adding new data and has the risk of not Perfectly the converted data from exel to .sql and the system used is offline so that students can only use the system if they are on campus by using one academic computer that is connected to the academic database. Based on these problems, an information system that facilitates website-based academic performance is needed so that it can be accessed online, so that students can view academic information without having to come to campus. The result of the research is an academic system website application using codeigniter 3.1.11 framework as the basis of the system which has a relatively small size, so it is accessed more quickly so that students can access information easily.

Keywords: Academic, Information System, Website
\end{abstract}

Alamat Korespondensi : Jl. Letnan Jenderal Suprapto No.73 Kebumen, Jawa Tengah, Indonesia 55431 This work is licensed under a Creative Commons Attribution-NonCommercial 4.0 International License. 


\section{PENDAHULUAN}

Penggunaan sistem informasi sudah sangat melekat pada kehidupan manusia di era modern, memiliki peran penting sebagai fasilitas yang memudahkan manusia dalam mendapatkan informasi [1]. Sistem informasi juga menjadi penunjang pekerjaan manusia untuk mengelola banyaknya data yang tersimpan di database sebagai sumber informasi dari sistem informasi [2].

Lingkup bagian akademik merupakan bagian yang mengelola data dan informasi, penggunaan sistem informasi merupakan hal yang mutlak dibutuhkan bagian akademik dalam mengelola informasi akademik dan sebagai fasilitas agar mahasiswa bisa memperoleh informasi yang berkaitan dengan bagian akademik [3]. Mobilitas mahasiswa yang tinggi mengakibatkan segala bentuk informasi akademik wajib bisa diakses dari manapun untuk mengetahui informasi dari bagian akademik [4]. Sistem yang digunakan dari tahun 2019 mengalami kekurangan pada mekanisme penggunaan, penyimpanan dan aksesnya yang bersifat offline sehingga menjadi sulit untuk digunakan dan mengakibatkan sistem tersebut tidak bisa bekerja secara maksimal.

Agar terwujudnya fasilitas tersebut maka dibutuhkan pengembangan sistem akademik berbasis website agar bisa digunakan secara online oleh mahasiswa yang membutuhkan informasi dari bagian akademik secara lengkap dan responsive. Penggunaan framework codeigniter v3.1.11 merupakan pilihan tepat dilihat dari sisi perawatan dan penggunaan source code yang terbuka dan memiliki banyak plug-in yang dapat didapatkan dengan mudah di laman atau forum pengembang tingkat internasional [5] [6].

Berdasarkan analisa penulis, masalah informasi akademik yang terjadi di Politeknik Dharma Patria Kebumen, diantaranya (1) Sistem akademik yang masih menggunakan akses kabel jaringan yang terhubung dengan server akademik sehingga tidak bisa diakses dari luar kampus oleh mahasiswa, (2) Sistem akademik memiliki proses penginputan nilai yang cukup lama dan sulit digunakan sehingga kerap terjadi kesalahan dalam prosedur penginputan, (3) Belum memiliki option export data menjadi file exel sehingga perekapannya masih secara manual, dan (4) Sistem yang digunakan merupakan sistem dengan framework yang sudah tidak dikembangkan lagi oleh pengembangnya, sehingga tingkat keamanannya masih rendah.

Tujuan dari penelitian ini adalah untuk mengembangkan dan membuat sistem yang mudah digunakan dan berjalan secara online, yang meliputi kemudahan dalam penggunaan 
oleh akademik dalam mengelola informasi dan dengan membuat menjadi online agar mahasiswa bisa mengakses informasi tanpa harus datang ke kampus.

\section{MATERIAL DAN METODE}

\subsection{Material}

\subsubsection{Konsep Bagian Akademik}

Bagian Akademik merupakan salah satu bagian dari struktur organisasi pendidikan tinggi yang mengelola kegiatan perkuliahan seperti pembuatan jadwal kuliah, rekap data mahasiswa, rekap nilai, konsultasi mahasiswa terkait akademik dan informasi perkuliahan sehingga akademik memiliki peran yang penting dalam menyelenggarakan pendidikan tinggi.

\subsubsection{Konsep Sistem Informasi Akademik}

Sistem akademik merupakan fasilitas manajerial, berfungsi sebagai sistem yang digunakan bagian akademik untuk mengelola data akademik agar mempermudah rekap datanya seperti nilai mahasiswa yang harus tersimpan rapi dalam satu format data dan bisa di kelola oleh bagian akademik untuk di gunakan dalam berbagai keperluan akademik.

\subsubsection{Konsep Informasi}

Informasi merupakan sekumpulan data atau fakta yang diolah dan dikelola sedemikian rupa sehingga menghasilkan sesuatu yang bisa dipahami dan memiliki manfaat bagi penerimanya [7].

\subsubsection{Konsep Database}

Konsep database merupakan kumpulan data yang saling terhubung sesuai dengan kebutuhan administrasi yang mengelola. Umumnya databse ditunjukan dengan dibuatnya kunci dari table yang dibuat dengan kata lain satu table memiliki record [8].

\subsubsection{Konsep Website}

Website merupakan kumpulan halaman untuk menampilkan informasi baik teks, gambar, audio, video bersifat statis maupun dinamis yang halamannya dirangkai terhubung satu lainnya [9].

\subsubsection{Unified Modelling Language}

Unfied Modelling Language (UML) suatu metode perancangan secara visual untuk sistem berorientasi dengan objek. UML mendefinisikan dalam bentuk diagram antara lain Usecase 
Diagram, Class Diagram, Sequence Diagram, State Chart Diagram, Activity Diagram, Collaboration Diagram, Component Diagram, Deployment Diagram [10].

\subsubsection{Kebutuhan Pembangunan Sistem Akademik}

Kebutuhan pembangunan sistem akademik meliputi : a) Framework Codeigniter v3.1.11; b) Editor Text; c) Software desain gambar; d) XAMP; e) Hosting; f) Sub Domain; g) Komputer dan h) smartphone.

\section{$2.2 \quad$ Metode}

Dalam menyeselaikan permasalahan digunakan metode penelitian kualitatif dengan pendekatan deskriptif, yaitu penelitian untuk mendeskripsikan dan menganalisis prosedur, mekanisme, kebutuhan, akses dan mahasiswa saat menggunakan sistem tersebut. Penelitian ini bertujuan untuk mengembangkan dan memecahkan suatu masalah yang terjadi pada sistem informasi akademik dengan mengkaji ulang sistem tersebut. Teknik pengumpulan data yang penulis gunakan berupa wawancara serta observasi di bagian akademik Politeknik Dharma Patria.

Sedangkan metode pengembangan sistem akademik yang digunakan adalah model MVC. Model MVC (Model, View, Controller) salah satu model pengembangan website dinamis dengan menggunakan PHP maka dapat mempercepat pengembangan dalam membuat aplikasi website sehingga memudahkan menulis dalam membuat sistem informasi. Tahapan penelitian dengan implementasi MVC disajikan pada Gambar 1.

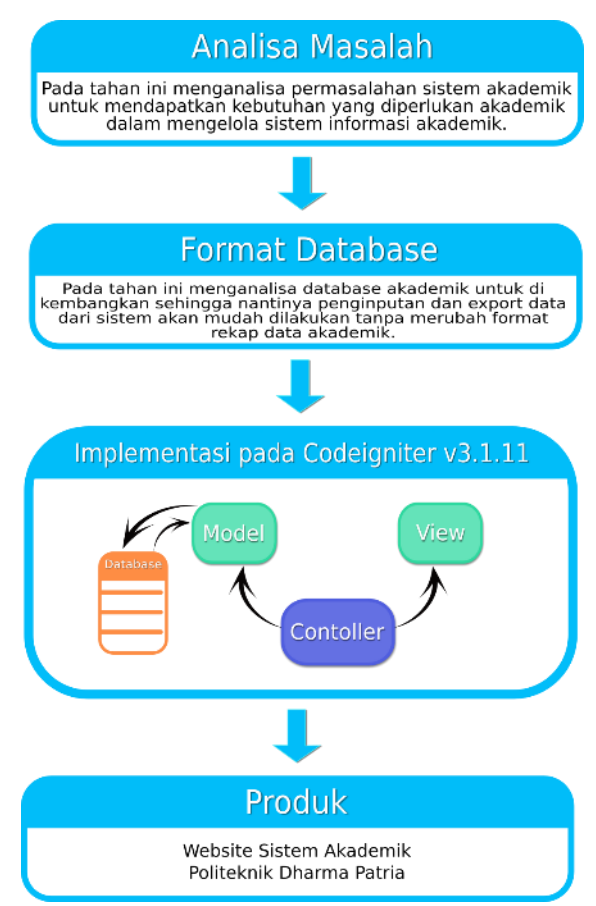

Gambar 1. Tahap Penelitian

Penjelasan dari tahapan penelitian yang terera pada Gambar 1 adalah sebagai berikut. 


\subsubsection{Analisa Masalah}

Penulis melakukan analisa permasalahan pada sistem informasi akademik dengan melakukan observasi dan wawancara dengan staf yang bertugas guna pengkajian yang lebih mendalam terkait kerusakan sistemnya antara lain penginputan jadwal, nilai, kalender akademik, yang tidak bisa dilakukan oleh sistem melainkan mengimport ke databse hosting dengan mengconvert exel ke sql. Dan juga sistem tidak bisa diakses secara online melainkan masih offline yang terhubung dengan kabel jaringan.

\subsubsection{Format Database}

Format database yang memiliki kode makul yang sudah berbeda dengan kurikulum yang berlaku membuat tidak terbacanya kode makul baru. Dan juga masih menggunakan driver mysql versi lama membuat kinerja database kurang maksimal.

\subsubsection{Implementasi CodeIgniter v3.1.11}

Dengan versi codeigniter 3.1.11 menggunakan driver mysql yang sudah update mysqli sehingga akses data ke database akan lebih cepat sehingga meringankan sistem informasi akademik dan didukung banyak plug-in yang bisa digunakan di versi v3.1.11

\subsubsection{Produk}

Produk dari penelitian ini berupa sistem informasi akademik yang mudah dalam penggunaannya dan bisa diakses secara online sehingga memudahkan mahasiswa dalam mengakses informasi dari akademik baik nilai, jadwal, kalender dan informasi yang berkaitan dengan akademik. Pembuatan style website yang responsive membuat ukuran website bisa responsive terhadap perangkat mobile maupun desktop.

\section{HASIL DAN PEMBAHASAN}

\subsection{Perancangan Sistem}

Perancangan sistem informasi akademik dibuat berbentuk tahapan untuk mempersiapkan proses implementasi pada framework codeigniter 3.1.11 dan berguna memberikan gambaran tentang sistem yang dikembangkan. Terdapat 2 level pengguna yaitu Level Admin dan Level User / Mahasiswa. Perancangan sistem informasi akademik penulis uraikan sebagai berikut:

\subsubsection{Masukan Level Admin}

Level admin memiliki masukan atau penginputan data akademik yang akan diakses oleh mahasiswa dan admin memiliki option untuk mengexport data sebagai rekap data pada sistem akademik. Adapun perancangan masukan yang diusulkan disajikan pada Tabel 1. 
Tabel 1. Masukan Sistem Informasi Akademik Level Admin

\begin{tabular}{|c|c|c|c|c|c|}
\hline No & Nama Masukan & Sumber & Fungsi & Frekuensi & Aktor \\
\hline 1. & Data Jadwal & $\begin{array}{l}\text { Data yang dibuat } \\
\text { akademik }\end{array}$ & $\begin{array}{l}\text { Memasukan data } \\
\text { jadwal kuliah }\end{array}$ & Setiap semester & $\begin{array}{c}\text { Operator SI } \\
\text { Akademik }\end{array}$ \\
\hline 2. & Data Nilai & $\begin{array}{c}\text { Data yang diserahkan } \\
\text { dari dosen ke } \\
\text { akademik }\end{array}$ & $\begin{array}{l}\text { Memasukan data } \\
\text { nilai }\end{array}$ & $\begin{array}{l}\text { Setiap semester / } \\
\text { update data }\end{array}$ & $\begin{array}{c}\text { Operator SI } \\
\text { Akademik }\end{array}$ \\
\hline 3. & $\begin{array}{c}\text { Data Kalender } \\
\text { akademik }\end{array}$ & $\begin{array}{c}\text { Data yang sudah } \\
\text { dibuat oleh akademik }\end{array}$ & $\begin{array}{c}\text { Masukan data } \\
\text { kalender akademik }\end{array}$ & Setiap semester & $\begin{array}{c}\text { Operator SI } \\
\text { Akademik }\end{array}$ \\
\hline 4. & Data mahasiswa & $\begin{array}{c}\text { Rekap data } \\
\text { mahasiswa akademik }\end{array}$ & $\begin{array}{l}\text { Memasukan data } \\
\text { mahasiswa }\end{array}$ & $\begin{array}{c}\text { Setiap ada } \\
\text { mahasiswa baru }\end{array}$ & $\begin{array}{l}\text { Operator SI } \\
\text { Akademik }\end{array}$ \\
\hline 5. & $\begin{array}{c}\text { Data } \\
\text { Pengumuman }\end{array}$ & Data dari akademik & $\begin{array}{c}\text { Masukan } \\
\text { pengumunan }\end{array}$ & $\begin{array}{c}\text { Setiap ada } \\
\text { informasi } \\
\text { terbaru }\end{array}$ & $\begin{array}{c}\text { Operator SI } \\
\text { Akademik }\end{array}$ \\
\hline 6. & Data Ujikom & $\begin{array}{c}\text { Rekap data ujikom } \\
\text { akademik }\end{array}$ & $\begin{array}{c}\text { Masukan data } \\
\text { ujikom }\end{array}$ & $\begin{array}{l}\text { Setiap sudah } \\
\text { terekap data } \\
\text { ujikom }\end{array}$ & $\begin{array}{l}\text { Operator SI } \\
\text { Akademik }\end{array}$ \\
\hline 7. & Data KSK & Rekap data KSK & Masukan data KSK & $\begin{array}{l}\text { Setiap sudah } \\
\text { terekap data } \\
\text { KSK }\end{array}$ & $\begin{array}{l}\text { Operator SI } \\
\text { Akademik }\end{array}$ \\
\hline
\end{tabular}

\subsubsection{Keluaran Level Admin}

Keluaran Level Admin merupakan rincian output data apa saja yang dihasilkan dalam sistem informasi akademik yang hanya digunakan oleh admin. Berikut ini adalah rancangan keluaran level admin pada sistem informasi akademik disajikan pada Tabel 2.

Tabel 2. Keluaran Sistem Informasi Akademik Level Admin

\begin{tabular}{cccccc}
\hline No & Nama Keluaran & Sumber & Fungsi & Frekuensi & Keterangan \\
\hline 1. & Data diri Mahasiswa & $\begin{array}{c}\text { Database } \\
\text { Akademik }\end{array}$ & $\begin{array}{c}\text { Mengetahui } \\
\text { biodatanya }\end{array}$ & $\begin{array}{c}\text { Setiap } \\
\text { dibutuhkan }\end{array}$ & $\begin{array}{c}\text { Operator bisa } \\
\text { mencetak data }\end{array}$ \\
\hline 2. & Report Nilai & $\begin{array}{c}\text { Database } \\
\text { Akademik }\end{array}$ & $\begin{array}{c}\text { Mengetahui } \\
\text { nilai untuk } \\
\text { akademik }\end{array}$ & $\begin{array}{c}\text { Setiap } \\
\text { dibutuhkan }\end{array}$ & $\begin{array}{c}\text { Operator bisa } \\
\text { mencetak data }\end{array}$ \\
\hline R. & Report Ujikom & $\begin{array}{c}\text { Database } \\
\text { Akademik }\end{array}$ & $\begin{array}{c}\text { Mengetahui } \\
\text { nilai ujikom }\end{array}$ & $\begin{array}{c}\text { Setiap } \\
\text { dibutuhkan }\end{array}$ & $\begin{array}{c}\text { Operator bisa } \\
\text { mencetak data }\end{array}$ \\
\hline 4. & Report KSK & $\begin{array}{c}\text { Database } \\
\text { Akademik }\end{array}$ & $\begin{array}{c}\text { Mengetahui } \\
\text { data ksk } \\
\text { mahasiswa }\end{array}$ & $\begin{array}{c}\text { Setiap } \\
\text { dibutuhkan }\end{array}$ & $\begin{array}{c}\text { Operator bisa } \\
\text { mencetak data }\end{array}$ \\
\hline
\end{tabular}




\subsubsection{Masukan Level User}

Level user memiliki rancangan masukan untuk mempermudah atau fasilitas lain untuk mahasiswa. Adapun rancangan masukan untuk level user disajikan pada Tabel 3.

Tabel 3. Masukan Sistem Informasi Akademik Level User

\begin{tabular}{|c|c|c|c|c|c|}
\hline No & Nama Masukan & Sumber & Fungsi & Frekuensi & Keterangan \\
\hline 1. & $\begin{array}{l}\text { Input pencarian jadwal } \\
\text { mata kuliah }\end{array}$ & $\begin{array}{c}\text { Database } \\
\text { Akademik }\end{array}$ & $\begin{array}{c}\text { Mahasiswa } \\
\text { mengetahui } \\
\text { jadwal kuliah } \\
\text { yang dicari }\end{array}$ & $\begin{array}{c}\text { Setiap } \\
\text { dibutuhkan }\end{array}$ & Mahasiswa \\
\hline 2. & $\begin{array}{l}\text { Update biodata } \\
\text { mahasiswa }\end{array}$ & Mahasiswa & $\begin{array}{c}\text { Merubah } \\
\text { biodata yang } \\
\text { salah di } \\
\text { sistem } \\
\text { akademik }\end{array}$ & $\begin{array}{c}\text { Setiap } \\
\text { dibutuhkan }\end{array}$ & Mahasiswa \\
\hline 3. & $\begin{array}{l}\text { Input pengaduan / } \\
\text { keluhan }\end{array}$ & $\begin{array}{c}\text { Database } \\
\text { Akademik } \\
\text { dan database } \\
\text { direktur }\end{array}$ & $\begin{array}{c}\text { Sebagai } \\
\text { sarana } \\
\text { pengaduan / } \\
\text { keluhan } \\
\text { mahasiswa } \\
\end{array}$ & $\begin{array}{c}\text { Setiap } \\
\text { dibutuhkan }\end{array}$ & Mahasiswa \\
\hline
\end{tabular}

\subsubsection{Keluaran Level User}

Level user memiliki rancangan masukan untuk mempermudah atau fasilitas lain untuk mahasiswa. Adapun rancangan masukan untuk level user disajikan pada Tabel 4.

Tabel 4. Keluaran Sistem Informasi Akademik Level User

\begin{tabular}{cccccc}
\hline No & Nama Masukan & Sumber & Fungsi & Frekuensi & Keterangan \\
\hline 1. & Laporan nilai mahasiswa & $\begin{array}{c}\text { Database } \\
\text { Akademik }\end{array}$ & $\begin{array}{c}\text { Menampilkan data } \\
\text { nilai }\end{array}$ & Setiap di akses & Mahasiswa \\
\hline 2. & Laporan nilai ujikom & $\begin{array}{c}\text { Database } \\
\text { Akademik }\end{array}$ & $\begin{array}{c}\text { Menampilkan data } \\
\text { nilai Ujikom }\end{array}$ & Setiap di akses & Mahasiswa \\
\hline 3. & Jadwal kuliah & $\begin{array}{c}\text { Database } \\
\text { Akademik }\end{array}$ & $\begin{array}{c}\text { Menampilkan data } \\
\text { jadwal kuliah }\end{array}$ & Setiap di akses & Mahasiswa \\
\hline 4. & Laporan KSK & $\begin{array}{c}\text { Database } \\
\text { Akademik }\end{array}$ & $\begin{array}{c}\text { Menampilkan data } \\
\text { KSK }\end{array}$ & Setiap di akses & Mahasiswa \\
\hline
\end{tabular}

\subsubsection{Rancangan Fungsional}

Rancangan fungsional adalah ilustrasi sistem informasi akademik yang akan bangun di bagian akademik politeknik dharma patria, rancangan ini dibuat menggunakan bahasa pemodelan UML (Unified Modelling Language) sebagai berikut: 


\subsubsection{Use Case Diagram}

Use case diagram membuat gambaran interaksi antara sistem dan aktor, berfungsi untuk mendeskripsikan tipe interaksi antara pengguna sistem dengan sistemnya. Use case diagram disajikan pada Tabel 5.

Tabel 5. Deskripsi Use Case Diagram Sistem Informasi Akademik

\begin{tabular}{|c|c|c|}
\hline No & Use Case & Deskripsi \\
\hline 1. & Login pengguna & $\begin{array}{l}\text { Proses validasi akses untuk user baik mahasiswa maupun admin jika } \\
\text { akan masuk ke sistem informasi akademik }\end{array}$ \\
\hline 2. & $\begin{array}{l}\text { Import Data } \\
\text { Nilai }\end{array}$ & Proses menambah data nilai terbaru ke database \\
\hline 3. & $\begin{array}{l}\text { Import Data } \\
\text { Jadwal }\end{array}$ & Proses menambah jadwal terbaru ke database \\
\hline 4. & $\begin{array}{l}\text { Import Data } \\
\text { Mahasiswa }\end{array}$ & Proses menambahkan data mahasiswa baru \\
\hline 5. & Import Kaldik & Proses menambahkan kalender akademik \\
\hline 6. & Import data KSK & Proses menambahkan data nilai ksk \\
\hline 7. & $\begin{array}{l}\text { Import data } \\
\text { Ujikom }\end{array}$ & Proses menambahkan data nilai ujikom \\
\hline 8. & Add jadwal KSK & membuat jadwal KSK \\
\hline 9. & $\begin{array}{l}\text { Add Jadwal } \\
\text { Ujikom }\end{array}$ & Membuat jadwal ujikom \\
\hline 10. & $\begin{array}{l}\text { Add } \\
\text { pengumuman }\end{array}$ & Menambahkan pengumuman \\
\hline
\end{tabular}

Gambar use case diagram disajikan pada Gambar 2.

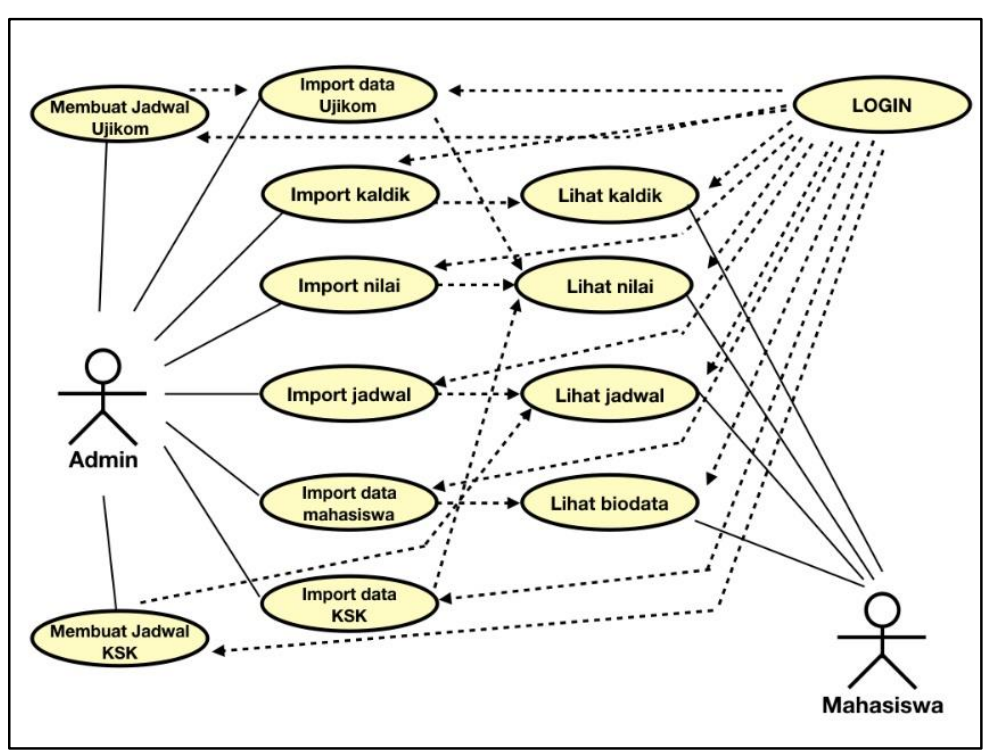

Gambar 2. Use Case Diagram Sistem Informasi Akademik

\subsubsection{Class Diagram}

Class Diagram disajikan pada Gambar 3. 


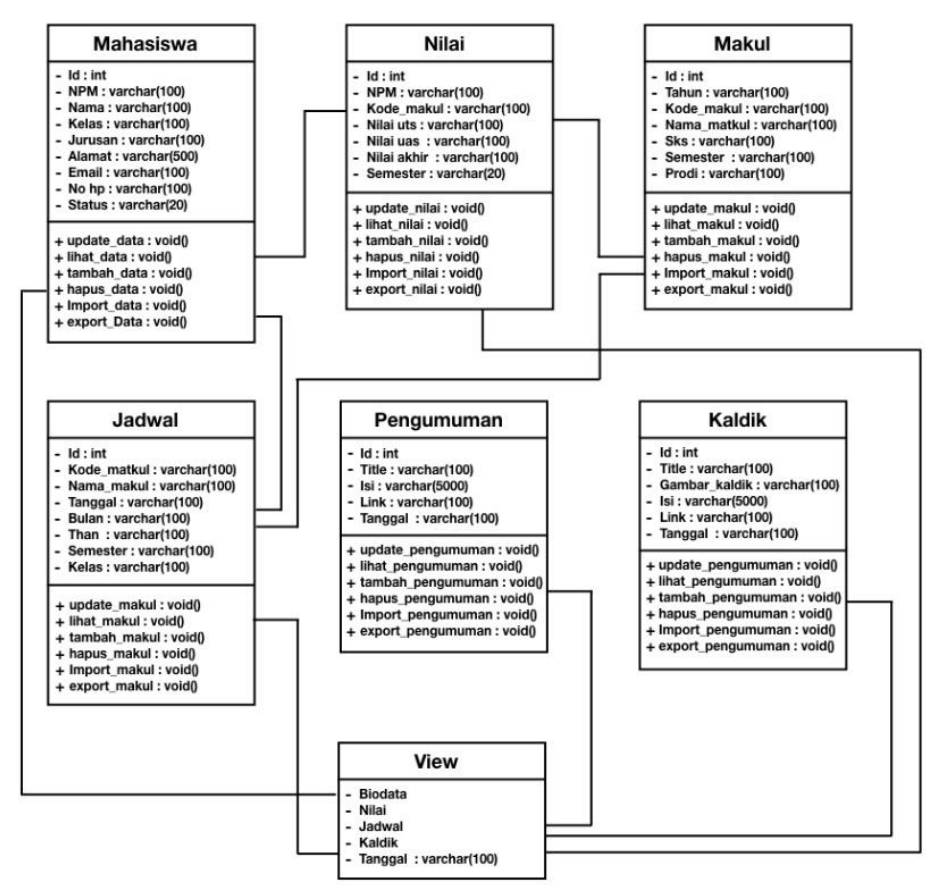

Gambar 3. Class Diagram Sistem Informasi Akademik

\subsubsection{Implementasi Sistem Informasi Akademik}

Implementasi sistem dilakukan kepada bagian akademik dan langsung dilakukan uji coba dengan memasukan data mahasiswa dengan hasil tanggapan yang positif karena sistem lama yang digunakan tidak bisa digunakan secara online, pada sistem baru ini bisa langsung digunakan secara online. Tampilan halaman login dari sistem informasi akademik disajikan pada Gambar 4.

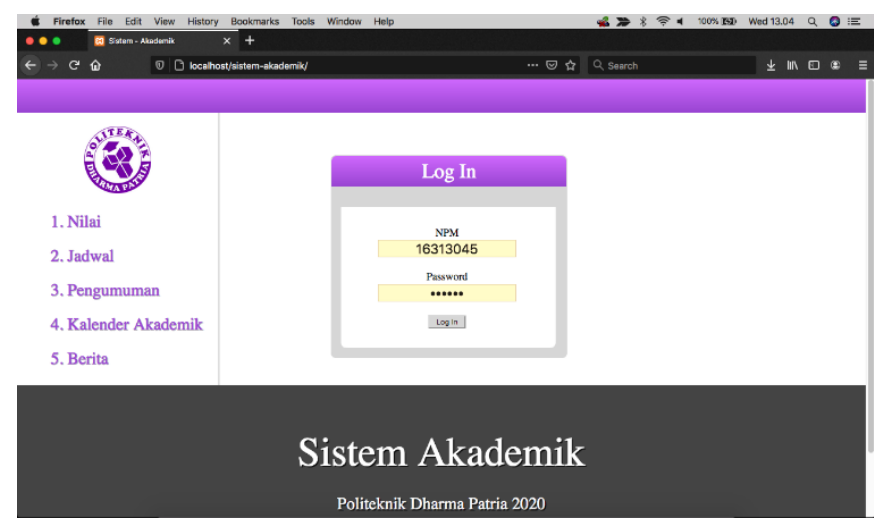

Gambar 4. Tampilan Halaman Login

Tampilan halaman dashboard mahasiswa dari sistem informasi akademik disajikan pada Gambar 5. 


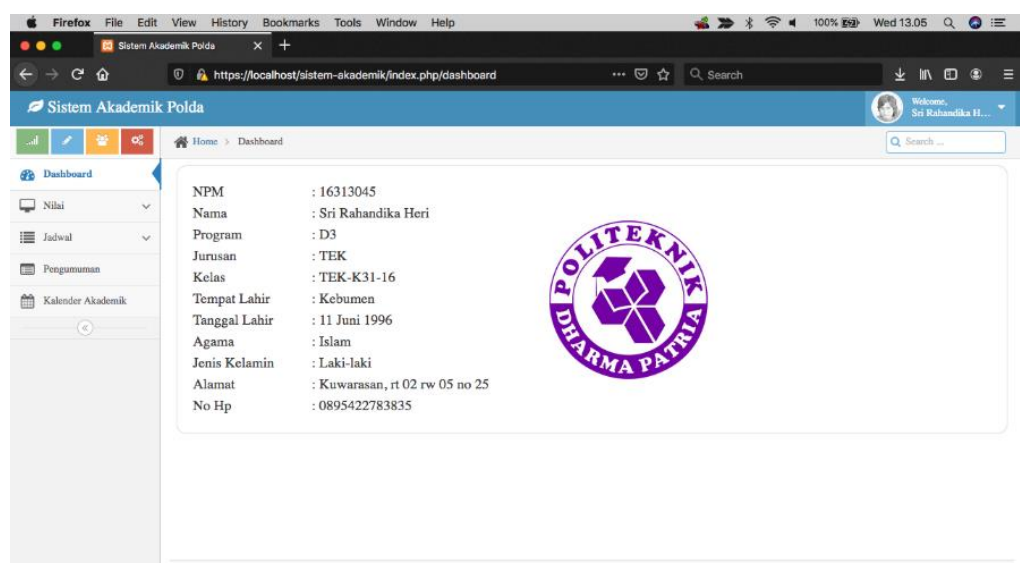

Gambar 5. Tampilan Dashboard Mahasiswa

Tampilan halaman informasi nilai dari sistem informasi akademik disajikan pada Gambar 6.

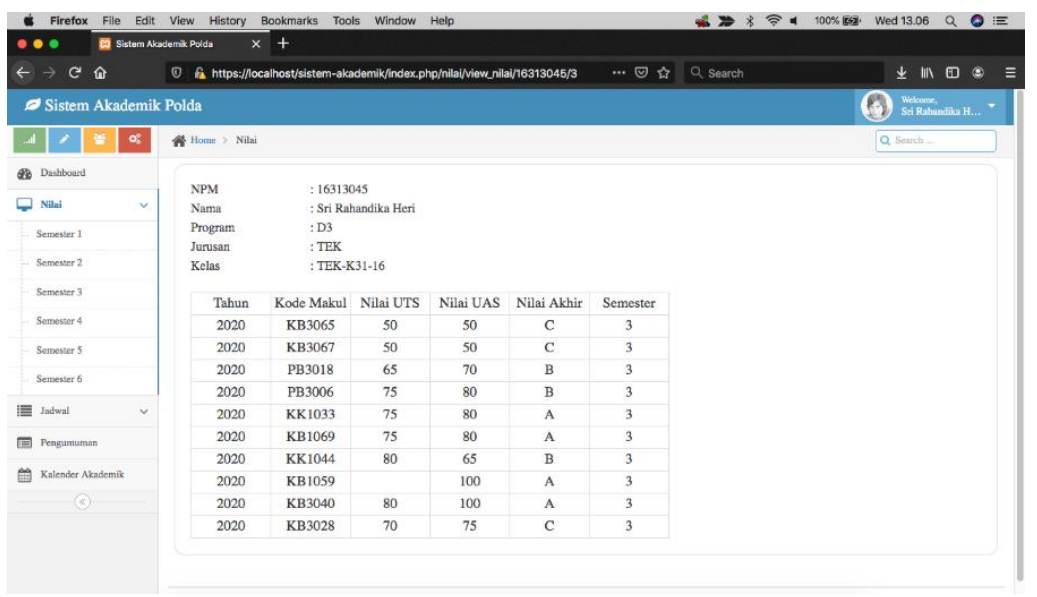

Gambar 6. Tampilan Halaman Informasi Nilai

\section{KESIMPULAN}

Sistem informasi akademik yang berjalan di politeknik dharma patria, masih belum sempurna dalam integrasi dengan webservice pddikti sehingga belum bisa langsung mengupload pelaporan data per semester. Untuk mengatasi masalah tersebut dibutuhkan pendalaman programing yang di gunakan pada webservice pddikti sehingga pelaporan feeder bisa secara kolektif untuk mempersingkat waktu kerja pelaporan

\section{REFERENSI}

[1] Hartono, Bambang, 2013, Sistem Informasi Manajemen Berbasis Komputer, Rineka Cipta: Jakarta.

[2] Mulyani, Isnawati., dkk, 2012, Pengembangan Short Message Service (SMS) Gateway Layanan Informasi Akademik, Buku Sakti Webmaster: Jakarta.

[3] Nugroho, Adi, 2009, Rekayasa Perangkat Lunak Menggunakan UML dan Java, Andi : Yogyakarta.

[4] O'Brien \& Marakas, 2013, Management Information System. Sixteenth Edition, McGraw-Hill/Irwin: New York. 
[5] Subhan, Mohamad, 2012, Analisa dan Perancangan Sistem, Lentera Ilmu Cendikia : Jakarta

[6] S. ANHAR, Panduan Menguasai PHP dan MySQL Secara Otodidak. 2010. Jakarta Selatan: Mediakita,

[7] E. Savitri, "Perancangan Sistem Informasi Penggajian Karyawan Pada CV.Wastam Menggunakan Model Fast," STMIK Atma Luhur Pangkalpinang, 2019.

[8] John A. Zachman, "The Concise Definition of The Zachman Framework," Zachman International, Inc., 2008. https:/ / www.zachman.com/about-the-zachman-framework (accessed Jun. 12, 2020).

[9] Waluyo, A. Perancangan Website Dinas Pendidikan Pemuda Dan Olah Raga (Studi Kasus Dinas Pendidikan Pemuda Dan Olah Raga Kabupaten Kebumen). J-SAKTI (Jurnal Sains Komputer dan Informatika), 1(2), 186-196. 2017.

[10] Andrey Andreev, "Open Source PHP Framework", CodeIgniter Github, 2020. https://github.com/bcit-ci/CodeIgniter (accessed Jun. 12, 2020). 